\title{
Association of acute kidney injury with readmissions after hospitalization for acute exacerbation of chronic obstructive pulmonary disease: a population-based study
}

Atsushi Hirayama $^{1,2^{*}}$, Tadahiro Goto ${ }^{1,3}$ and Kohei Hasegawa ${ }^{1}$

\begin{abstract}
Background: Little is known about the relationship between acute kidney injury (AKI) and outcomes after acute exacerbation of chronic obstructive pulmonary disease (AECOPD). We aimed to investigate associations between AKI and readmission risks after hospitalization for AECOPD.

Methods: A retrospective, population-based cohort study using State Inpatient Databases from seven U.S. states (Arkansas, California, Florida, lowa, Nebraska, New York, and Utah) from 2010 through 2013. We identified all adults (aged $\geq 40$ years) hospitalized for AECOPD during the study period. Among them, we further identified patients with a concurrent diagnosis of new AKI. The outcome measures were any-cause readmissions within 30 days and 90 days after hospitalization for AECOPD. To determine associations between AKI and readmission risk, we constructed Cox proportional hazards models examining the time-to-readmission. We also identified the primary reason of readmission.

Results: We identified 356,990 patients hospitalized for AECOPD. The median age was 71 years and $41.9 \%$ were male. Of these, 24,833 (7.0\%) had a concurrent diagnosis of AKI. Overall, patients with AKI had significantly higher risk of 30-day all-cause readmission compared to those without AKI (hazard ratio 1.47; 95\% Cl 1.43-1.51; $P<0.001$ ). Likewise, patients with AKI had significantly higher risk of 90-day all-cause readmission (hazard ratio 1.35; 95\% Cl 1.32-1.38; $P<0.001$ ). These associations remained significant after adjustment for confounders (both $P<0.05$ ). Additionally, patients with AKI were likely to be readmitted for non-respiratory reasons including sepsis, acute renal failure, and congestive heart failure.
\end{abstract}

Conclusions: Among patients hospitalized for AECOPD, patients with AKI were at higher risk of 30-day and 90-day readmission, particularly with non-respiratory reasons.

Keywords: Acute exacerbation of COPD, Acute kidney injury, Readmission, Population-based study

\footnotetext{
* Correspondence: ath877@mail.harvard.edu

'Department of Emergency Medicine, Massachusetts General Hospital, Boston, MA, 125 Nashua Street, Suite 920, Boston, MA, USA

${ }^{2}$ Public Health, Department of Social Medicine, Osaka University Graduate School of Medicine, 2-2, Yamadaoka, Suita, Osaka, Japan

Full list of author information is available at the end of the article
}

(c) The Author(s). 2020 Open Access This article is licensed under a Creative Commons Attribution 4.0 International License, which permits use, sharing, adaptation, distribution and reproduction in any medium or format, as long as you give appropriate credit to the original author(s) and the source, provide a link to the Creative Commons licence, and indicate if changes were made. The images or other third party material in this article are included in the article's Creative Commons licence, unless indicated otherwise in a credit line to the material. If material is not included in the article's Creative Commons licence and your intended use is not permitted by statutory regulation or exceeds the permitted use, you will need to obtain permission directly from the copyright holder. To view a copy of this licence, visit http://creativecommons.org/licenses/by/4.0/. The Creative Commons Public Domain Dedication waiver (http://creativecommons.org/publicdomain/zero/1.0/) applies to the data made available in this article, unless otherwise stated in a credit line to the data. 


\section{Background}

Acute exacerbation of chronic obstructive pulmonary disease (AECOPD) is a major public health burden accounting for 600,000 hospitalizations in the US annually [1]. As a readmission after hospitalization for AECOPD is a common and costly event [2, 3], investigating its characteristics and risks are important. Acute kidney injury (AKI) is another important public health burden; the incidence of AKI has been reported to be $5 \%$ of hospitalized patients and $30 \%$ of critically ill patients [4]. These two acute conditions share similar pathobiology in the development and progression, such as systemic inflammation [5].

The literature has reported relationships between these two conditions. For example, according a study using clinical database of the United Kingdom, the incidence and prevalence of AKI were higher in patients with COPD compared to those reported in previous studies in general populations and hospitalizations [6]. Additionally, cross-sectional studies have also reported that patients hospitalized for AECOPD with AKI had higher in-hospital mortality, compared to those without AKI [6, 7]. Despite the clinical importance, no longitudinal study has investigated whether AKI is associated with the subsequent risk of readmissions in patients hospitalized for AECOPD - a population with large morbidity burden and healthcare use.

To address this knowledge gap, we aimed to investigate the association of AKI with all-cause readmissions within 30 and 90 days after hospitalization for AECOPD.

\section{Methods}

\section{Study design and setting}

We conducted a retrospective cohort study using large, population-based data from the Healthcare Cost and Utilization Project (HCUP) State Inpatient Database (SID) of seven geographically-dispersed US states (Arkansas, California, Florida, Iowa, Nebraska, New York, and Utah) from 2010 through 2013. The HCUP is a family of healthcare databases that are developed through a federal-state-industry partnership and sponsored by the Agency for Healthcare Research and Quality (AHRQ). The HCUP is the largest collection of longitudinal hospital care data in the US, with all-payer, encounter-level information. The HCUP SIDs capture all hospitalizations, regardless of source of disposition, from acute care, non-federal, general and other specialty hospitals within the participating states [8]. These seven states were selected for their high data quality, geographic distribution, and mainly because their data included unique encrypted patient identifiers that enable longitudinal follow-up of specific individuals across years (including identification of readmissions). The institutional review board of Massachusetts General Hospital approved this study.

\section{Study population}

We identified all hospitalized adult patients (aged > 40 years) with a principal discharge diagnosis of COPD, as defined by the International Classification of Diseases, Ninth Revision, Clinical Modification (ICD-9-CM) diagnosis codes of 491.21, 491.22, 491.8, $491.9,492.8,493.20,493.21,493.22$, and 496, or those with a primary diagnosis of respiratory failure (codes $518.81,518.82,518.84$, and 799.1) and a secondary diagnosis of COPD $[9,10]$. In the current analysis, we used only the first hospitalizations of the eligible patients during the study period. We also excluded patients who left the hospital against medical advice, those who died in-hospital at their index hospitalization, those who were transferred to another acute-care facility, and out-of-state residents.

\section{Measurements}

The SID contain information on the patient characteristics, including demographics (age, sex, and race/ethnicity), primary insurance type (payer), quartiles for estimated household income, patient residence, ICD-9$C M$ diagnosis and procedure codes, patient comorbidities (29 Elixhauser comorbidity measures and arrhythmia), hospital course (e.g., hospital length-of-stay, in-hospital death), and disposition.

\section{Primary exposure}

The primary exposure was the development of inhospital AKI during the index hospitalization for AECOPD, as defined by the ICD-9-CM diagnostic codes of $584.5,584.6,584.7,584.8$, and 584.9 in any diagnostic fields [11-13], with excluding AKI as an admission diagnosis. Additionally, we also identified AKI with the use of dialysis, defined as having both of AKI (diagnostic codes, 584.5-584.9) and hemodialysis (procedure code of 39.95 or diagnostic code of V45.1, V56.0 or V56.1) $[11,12]$.

\section{Outcome measures}

The outcome measures were readmission attributable to any cause within 30 and 90 days of discharge from the index hospitalization for AECOPD. In the COPD literature, 30-day readmission rates have been investigated $[9,13,14]$ in the context of the Centers for Medicare and Medicaid Services' Hospital Readmissions Reduction Program (HRRP) [15]; 90-day readmission rates have also been recognized as an important clinical indicator [16, 17]. The secondary outcome measure was the primary discharge diagnosis of the readmission. To make data presentation and 
interpretation more meaningful, we consolidated the principal discharge diagnoses (>14,000 ICD-9-CM diagnosis codes) into 285 mutually exclusive diagnostic categories by using the AHRQ-defined Clinical Classifications Software (CCS) [18].

\section{Statistical analysis}

First, we compared the patient characteristics between patients with and without AKI by using Wilcoxon rank sum test or chi-squared test, as appropriate. We also compared Kaplan-Meier curves between the two groups with the use of the log-rank test. Next, we modeled the time-to-readmission by fitting Cox proportional hazards models with generalized estimating equations accounting for patient clustering within hospitals (e.g., severity of patients, physicians' preference in disease management within hospitals) [19, 20]. The time-to-readmission for each patient was defined as the period from the discharge to when the first readmission occurred within the 30-day and 90day follow-up periods. Patients who did not have an outcome were censored at 30 days (or 90 days) from discharge or in-hospital death during the corresponding follow-up period, whichever occurred first. We fitted Cox proportional hazards model with adjustment for potential confounders, such as age, sex, race/ethnicity, primary insurance, quartiles for median household income, residential status, length-of-stay at the index hospitalization, hospital state, and 28 Elixhauser comorbidities as well as arrhythmia [21, 22]. Furthermore, as sensitivity analyses, we repeated the analysis with stratifications by age category (40-64 years and $\geq 65$ years) and sex as previous studies have reported age- and sex-related differences in the readmission rate after hospitalization for AECOPD [9, 13, 14]. Additionally, we repeated the analysis with stratifications by presence of renal failure (or chronic kidney disease [CKD]) indicated in the Elixhauser comorbidities. Lastly, we compared the 30-day and 90day readmission rates and calculated the unadjusted and adjusted hazard ratios among patients without AKI, those with AKI without dialysis use, and healthcare use and with AKI and dialysis use. We primarily conducted an available case analysis, and examined consistency with the results of complete case analysis. All analyses used STATA 14.0 (STATA Corp, College Station, TX). All $P$ values were two-tailed, with $P<$ 0.05 considered statistically significant.

\section{Results}

We first identified 385,604 patients hospitalized for AECOPD in the seven U.S. states. From these, we excluded 6911 patients who left the hospital against medical advice, 5613 patients who died in-hospital at the index hospitalization, 4378 patients who were transferred to another acute-care facility, and 11,712 out-of-state residents. Finally, a total of 356,990 patients were eligible for the present analysis (Supplemental Figure 1). Overall, the median age was 71 years, $41.9 \%$ were male, and $73.9 \%$ were non-Hispanic white; $7.0 \%$ had a new diagnosis of AKI during the index hospitalization. The patient characteristics differed between patients with AKI and those without AKI (Table 1)-for example, the AKI group was more likely to be older and male. Overall, 58,076 (16.3\%) patients had at least one readmission within 30 days after their index hospitalization, and 112,917 (31.6\%) had at least one readmission within 90 days after their hospitalization (Supplemental Table 1).

The Kaplan-Meier survival curves demonstrated a significant difference in the risk of all-cause 30-day and 90-day readmission between patients with AKI and those without AKI $(P<0.001$, Figs. 1 and 2$)$. In the unadjusted Cox proportional hazards model, patients with AKI had a significantly higher risk of 30day readmission when compared to those without AKI (hazard ratio [HR] 1.47; 95\%CI 1.43-1.51; $P<$ 0.001; Table 2). In the adjusted model, the significant association persisted (HR 1.07; 95\%CI 1.04-1.11; $P<$ 0.001 ). Likewise, with regard to all-cause 90 -day readmission, patients with AKI had a significantly higher risk of 90-day readmission (HR 1.35; 95\%CI 1.32-1.38; $P<0.001$; Table 3 ). The significant association also persisted after adjustment for potential confounders (HR 1.03; 95\%CI 1.00-1.05; $P=0.04$ ). With stratifications by age, sex and presence of CKD indicated in the Elixhauser comorbidities, these associations remained significant in patients aged $\geq 65$ years, women, and patients without CKD (all $P<0.05$, Tables 2 and 3). There was a statistically significant interaction between AKI and the presence of CKD on the risks of 30-day and 90-day readmission after hospitalization for AECOPD (both $\mathrm{P}_{\text {interaction }}<0.05$ ). The complete case analyses also showed consistent results (Supplemental Tables 2, 3 and 4). In the stratified analysis by dialysis use, both AKI groups had higher 30-day and 90-day readmission rates, compared with those without AKI (unadjusted $P<0.001$; Supplemental Table 5). Despite the limited statistical power in this stratified analysis, the association between AKI and higher 30-day readmission rate remained significant after adjustment in the AKI without hemodialysis group.

Among patients without $\mathrm{AKI}$, the most frequent primary cause for 30-day readmission was COPD, followed by pneumonia, respiratory failure, and asthma; Table 4). By contrast, patients with AKI were more likely to be readmitted due to non-respiratory 
Table 1 Characteristics of patients hospitalized for acute exacerbation of chronic obstructive pulmonary disease by acute kidney injury

\begin{tabular}{|c|c|c|c|}
\hline \multirow[t]{2}{*}{ Characteristics } & \multirow{2}{*}{$\begin{array}{l}\text { AKI } \\
n=24,833 \\
(7.0 \%)\end{array}$} & \multirow{2}{*}{$\begin{array}{l}\text { Non-AKI } \\
n=332,157 \\
(93.0 \%)\end{array}$} & \multirow[t]{2}{*}{$\boldsymbol{P}$ value } \\
\hline & & & \\
\hline Age (year), median (IQR) & $76(67-83)$ & $70(60-80)$ & $<0.001$ \\
\hline Male & $12,605(50.8)$ & $136,949(41.2)$ & $<0.001$ \\
\hline Race/ethnicity & & & $<0.001$ \\
\hline Non-Hispanic white & $17,375(72.3)$ & $237,741(74.0)$ & \\
\hline Non-Hispanic black & $2848(11.9)$ & $34,030(10.6)$ & \\
\hline Hispanic & $2593(10.8)$ & $35,333(11.0)$ & \\
\hline Others & $1217(5.1)$ & $14,034(4.5)$ & \\
\hline Primary health insurance & & & $<0.001$ \\
\hline Medicare & $20,089(81.4)$ & $233,472(70.3)$ & \\
\hline Medicaid & $1817(7.4)$ & $36,878(11.1)$ & \\
\hline Private & $1682(6.8)$ & $38,944(11.7)$ & \\
\hline Others & $1093(4.4)$ & $22,698(6.9)$ & \\
\hline Median household income quartile & & & $<0.001$ \\
\hline 1 (lowest) & $7216(29.7)$ & $103,211(31.9)$ & \\
\hline 2 & $6230(25.6)$ & $89,605(27.7)$ & \\
\hline 3 & $5931(24.4)$ & $76,312(23.6)$ & \\
\hline 4 (highest) & $4927(20.3)$ & $54,794(16.9)$ & \\
\hline Patient residence & & & $<0.001$ \\
\hline Metropolitan & $22,529(90.8)$ & $288,858(87.0)$ & \\
\hline Non-metropolitan & $2304(9.2)$ & $43,299(13.0)$ & \\
\hline \multicolumn{4}{|l|}{ Selected comorbidities ${ }^{a}$} \\
\hline Congestive heart failure & $11,326(45.6)$ & $78,120(23.5)$ & $<0.001$ \\
\hline Depression & $3348(13.5)$ & $52,482(15.8)$ & $<0.001$ \\
\hline Diabetes & $10,415(41.9)$ & $93,904(28.3)$ & $<0.001$ \\
\hline Hypertension & $20,125(81.0)$ & $219,396(66.1)$ & $<0.001$ \\
\hline Obesity & $5048(20.3)$ & $50,795(15.3)$ & $<0.001$ \\
\hline Peripheral artery disease & $2967(11.9)$ & $24,961(7.5 \%)$ & $<0.001$ \\
\hline Chronic kidney disease & $13,481(54.3)$ & $34,518(10.4)$ & $<0.001$ \\
\hline Hospital length-of-stay & & & $<0.001$ \\
\hline$<3$ days & $3599(14.5)$ & $97,877(29.5)$ & \\
\hline $3-4$ days & $7223(29.1)$ & $117,624(35.4)$ & \\
\hline $5-6$ days & $5407(21.8)$ & $60,523(18.2)$ & \\
\hline$\geq 7$ days & $8604(34.6)$ & $56,133(16.9)$ & \\
\hline Hospital state & & & $<0.001$ \\
\hline Arkansas & $1695(6.8)$ & $15,644(4.7)$ & \\
\hline California & $4561(18.4)$ & $63,913(19.2)$ & \\
\hline Florida & $10,295(41.5)$ & $135,717(40.9)$ & \\
\hline lowa & $764(3.1)$ & $11,825(3.6)$ & \\
\hline Nebraska & $536(2.2)$ & $7252(2.2)$ & \\
\hline New York & $6667(26.8)$ & $93,863(28.3)$ & \\
\hline Utah & $315(1.3)$ & $3943(1.2)$ & \\
\hline
\end{tabular}

Abbreviations: AKI Acute kidney injury, IQR Interquartile range

Data are shown as $n(\%)$ unless otherwise specified

${ }^{\text {a }}$ Selected from 29 Elixhauser comorbidity measures and arrhythmia 
diseases (e.g., sepsis, acute renal failure, congestive heart failure). The five most frequent causes of readmission were not different between 30-day and 90day readmissions after hospitalization for AECOPD (Table 4 and Supplemental Table 6).

\section{Discussion}

In this large population-based study of 356,990 patients hospitalized for AECOPD in the seven U.S. states, we found that patients with AKI had a 50\% higher risk of all-cause readmissions during 30 days after their index hospitalization when compared to those without AKI. This significant association persisted after the adjustment for potential confounders. The limited epidemiological literature has indicated the association of acute kidney disease with COPD [23]. For example, a retrospective cohort study using electronic medical records in Taiwan showed that COPD is associated with a higher risk of development of AKI [23]. Furthermore, among patients hospitalized for AECOPD, those with AKI had approximately 2 -fold higher mortality rate within 6 months compared to those without AKI [6]. Our findings based on the large population-based data corroborate these prior studies, and extend them by demonstrating the longitudinal association of AKI with a higher risk of all-cause readmission after hospitalization for AECOPD.

The underlying mechanisms of the observed association of AKI with higher risks of readmission after hospitalization for AECOPD warrant clarification. In the present study, part of the association was attributable to the differences in patient-level sociodemographic factors, hospital length-of-stay and comorbidities between the two target populations. However, despite the rigorous adjustment, AKI remained an independent risk factor for readmission in patients hospitalized for AECOPD. This finding suggests that there are other factors predisposing patients with AKI to worse clinical outcomes. One potential mechanism is impaired immunity following AKI $[24,25]$. Indeed, studies have showed that AKI is a risk factor for subsequent infection (e.g., incident active tuberculosis infection [26] and sepsis [27]). Consistently, we observed that the most frequent primary cause of readmission was sepsis in the patients with AKI, while the most common cause was COPD in those without AKI. Furthermore, AKI-related systemic inflammation [5] and volume overload [28] may add to the existent morbidity in patients hospitalized for AECOPD. These potential mechanisms may have independently or jointly contributed to worse disease control of COPD, exacerbation of existent comorbidities, and increased disease susceptibility, thereby leading to greater healthcare utilization in patients with concurrent AECOPD and AKI. Additionally, we also observed the age- and sex-related difference in the association of AKI with readmission risks after hospitalization for AECOPD. Consistently, previous epidemiologic studies have also indicated the age and sex-related difference in severity of AKI, morbidity and mortality after AKI in other disease populations $[6,12,29-33]$. These data collectively suggest the interplay between the patient biological characteristics

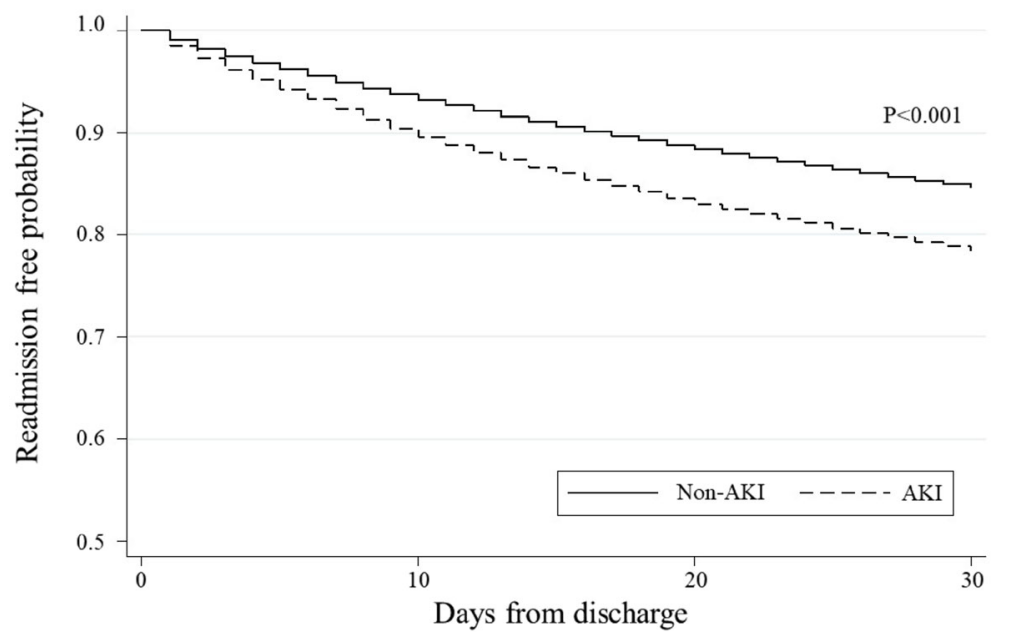

Fig. 1 Kaplan-Meier survival estimates of all-cause readmission risk during 30-day period after the index hospitalization for acute exacerbation of chronic obstructive pulmonary disease. Patients with acute kidney injury (AKI) had a significantly higher risk of all-cause readmission during 30day period after the index hospitalization, compared to those without AKI ( $\left.P_{\text {log-rank }}<0.001\right)$ 


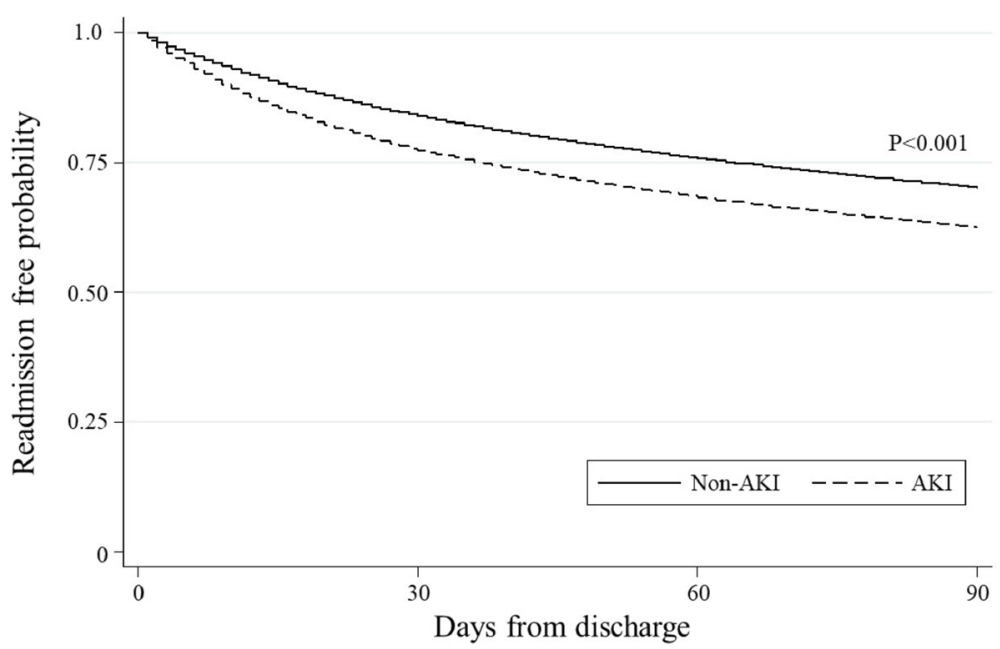

Fig. 2 Kaplan-Meier survival estimates of all-cause readmission risk during 90-day period after the index hospitalization for acute exacerbation of chronic obstructive pulmonary disease. Patients with acute kidney injury (AKI) had a significantly higher risk of all-cause readmission during 90day period after the index hospitalization, compared to those without $A K I\left(P_{\text {log-rank }}<0.001\right)$

(age, sex), AKI, and AECOPD, and their integrated contributions to subsequent morbidity risk, which merits further investigations.

Our study has several potential limitations. First, in this large population-based study, detailed information on renal function was unavailable. Yet, adjusting for the Elixhauser comorbidities should have accounted, at least partially, for potential confounding by this factor. Additionally, to account for the potential effect of AKI severity, we also performed the sensitivity analysis stratified by use of dialysis. Second, as we used administrative datasets, there may be misclassifications, such as misdiagnosis of AECOPD and AKI. Nevertheless, the ICD-9-CM codes for COPD are widely used $[8,9]$, and the HCUP data are rigorously tested and considered accurate [13, 34-36]. Additionally, while the literature showed that the ICD-9-CM codes for AKI had a high specificity and low

Table 2 Hazard ratio for all-cause readmission during 30-day periods after index hospitalization for acute exacerbation of chronic obstructive pulmonary disease, according to acute kidney injury, overall and stratified by age category and sex and chronic kidney disease

\begin{tabular}{|c|c|c|c|c|c|c|c|}
\hline & \multicolumn{2}{|c|}{ 30-day readmission rate } & \multicolumn{2}{|c|}{ Unadjusted model } & \multicolumn{2}{|l|}{ Adjusted model $^{a}$} & \multirow{2}{*}{$\begin{array}{l}\text { P for } \\
\text { interaction }\end{array}$} \\
\hline & AKI $(n=24,833)$ & Non-AKI $(n=332,157)$ & $\mathrm{HR}(95 \% \mathrm{Cl})$ & $P$-value & $\mathrm{HR}(95 \% \mathrm{Cl})$ & $P$-value & \\
\hline Overall $(n=356,990)$ & $22.4 \%$ & $15.8 \%$ & $1.47(1.43-1.51)$ & $<0.001$ & $1.07(1.04-1.11)$ & $<0.001$ & \\
\hline \multicolumn{8}{|l|}{ Age category } \\
\hline $40-64$ years $(n=122,362)$ & $20.9 \%$ & $14.0 \%$ & $1.52(1.43-1.63)$ & $<0.001$ & $1.03(0.96-1.10)$ & 0.45 & 0.13 \\
\hline$\geq 65$ years $(n=234,628)$ & $22.7 \%$ & $16.8 \%$ & $1.41(1.36-1.45)$ & $<0.001$ & $1.09(1.05-1.13)$ & $<0.001$ & \\
\hline \multicolumn{8}{|l|}{$\operatorname{Sex}^{b}$} \\
\hline Men $(n=149,333)$ & $22.0 \%$ & $16.7 \%$ & $1.36(1.30-1.41)$ & $<0.001$ & $1.03(0.99-1.08)$ & 0.14 & 0.07 \\
\hline Women $(n=207,436)$ & $22.7 \%$ & $15.2 \%$ & $1.56(1.50-1.62)$ & $<0.001$ & $1.12(1.07-1.17)$ & $<0.001$ & \\
\hline \multicolumn{8}{|l|}{ Chronic kidney disease $^{c}$} \\
\hline Chronic kidney disease $(n=47,999)$ & $27.7 \%$ & $24.2 \%$ & $1.14(1.09-1.18)$ & $<0.001$ & $1.03(0.99-1.07)$ & 0.24 & 0.01 \\
\hline No chronic kidney disease $(n=308,991)$ & $22.3 \%$ & $16.8 \%$ & $1.32(1.26-1.38)$ & $<0.001$ & $1.09(1.05-1.15)$ & $<0.001$ & \\
\hline
\end{tabular}

Abbreviations: AKI Acute kidney injury, HR Hazard ratio, Cl Confidence interval

${ }^{a}$ Cox proportional hazards model adjusting for age, sex, race/ethnicity, insurance status, estimated household income, residential status, hospital length-of-stay, hospital state, and Elixhauser comorbidity measures and arrhythmia with generalized estimating equations to account for patient clustering within hospitals ${ }^{b} 221$ patients with missingness on sex data

${ }^{\mathrm{c}}$ Chronic kidney disease was defined by the Elixhauser comorbidities 
Table 3 Hazard ratio for all-cause readmission during 90-day periods after index hospitalization for acute exacerbation of chronic obstructive pulmonary disease, according to acute kidney injury, overall and stratified by age category and sex and chronic kidney disease

\begin{tabular}{|c|c|c|c|c|c|c|c|}
\hline & \multicolumn{2}{|c|}{ 90-day Readmission rate } & \multicolumn{2}{|c|}{ Unadjusted model } & \multicolumn{2}{|l|}{ Adjusted model ${ }^{\mathbf{a}}$} & \multirow{2}{*}{$\begin{array}{l}P \text { for } \\
\text { interaction }\end{array}$} \\
\hline & AKI $(n=24,833)$ & Non-AKI $(n=332,157)$ & HR $(95 \% \mathrm{Cl})$ & $P$-value & $\mathrm{HR}(95 \% \mathrm{Cl})$ & $P$-value & \\
\hline Overall $(n=356,990)$ & $39.7 \%$ & $31.0 \%$ & $1.35(1.32-1.38)$ & $<0.001$ & $1.03(1.00-1.05)$ & 0.04 & \\
\hline \multicolumn{8}{|l|}{ Age category } \\
\hline $40-64$ years $(n=122,362)$ & $37.6 \%$ & $27.8 \%$ & $1.43(1.36-1.50)$ & $<0.001$ & $1.00(0.95-1.06)$ & 0.86 & 0.10 \\
\hline$\geq 65$ years $(n=234,628)$ & $40.2 \%$ & $32.8 \%$ & $1.29(1.26-1.32)$ & $<0.001$ & $1.03(1.00-1.06)$ & 0.03 & \\
\hline \multicolumn{8}{|l|}{ Sex } \\
\hline Men $(n=149,333)$ & $38,9 \%$ & $32.2 \%$ & $1.26(1.22-1.29)$ & $<0.001$ & $0.99(0.96-1.03)$ & 0.59 & 0.06 \\
\hline Women $(n=207,436)$ & $40.5 \%$ & $30.2 \%$ & $1.43(1.39-1.48)$ & $<0.001$ & $1.06(1.02-1.09)$ & 0.001 & \\
\hline \multicolumn{8}{|l|}{ Chronic kidney disease ${ }^{c}$} \\
\hline Chronic kidney disease $(n=47,999)$ & $43.0 \%$ & $40.9 \%$ & $1.06(1.03-1.09)$ & 0.001 & $0.98(0.95-1.02)$ & 0.21 & $<0.001$ \\
\hline No chronic kidney disease $(n=308,991)$ & $35.7 \%$ & $29.9 \%$ & $1.22(1.18-1.26)$ & $<0.001$ & $1.04(1.00-1.07)$ & 0.04 & \\
\hline
\end{tabular}

Abbreviations: AKI Acute kidney injury, HR Hazard ratio, Cl Confidence interval

${ }^{a}$ Cox proportional hazards model adjusting age, sex, race/ethnicity, insurance status, estimated household income, residential status, hospital length-of-stay, hospital state, and Elixhauser comorbidity measures and arrhythmia with generalized estimating equations to account for patient clustering within hospitals ${ }^{b} 221$ patients with missingness on sex data

${ }^{\mathrm{c} C h r o n i c}$ kidney disease was defined by the Elixhauser comorbidities

sensitivity [37], underdiagnoses or misclassifications of AKI at the index hospitalization are likely to have occurred equally regardless of the subsequent outcomes, which would have biased our estimates toward the null. Third, SIDs do not capture information on outof-hospital deaths, which precluded us from accounting for this potential competing risk. In contrast, we accounted for the potential effect of in-hospital deaths during the follow-up periods. Fourth, as with any observational study, the causal inference of AKI with readmission risks might be confounded by unmeasured factors (e.g., access to ambulatory healthcare, patient's health behavior). Lastly, the studied data are not a random sample of all individuals with AECOPD in the U.S. However, the seven geographically-dispersed states represent approximately $27 \%$ of the U.S. population, thereby supporting the generalizability of our inferences.

\section{Conclusions}

In the large population-based database of 356,990 patients hospitalized for AECOPD across seven US states, we found that patients with AKI had a significantly higher risk of all-cause readmissions during

Table 4 The ten most frequent principal diagnoses of 30-day readmissions in patient hospitalized for acute exacerbation of chronic obstructive pulmonary disease, stratified by acute kidney injury

\begin{tabular}{|c|c|c|c|}
\hline \multicolumn{2}{|l|}{ Without AKI $(\boldsymbol{n}=50,984)$} & \multicolumn{2}{|l|}{ With AKI $(\boldsymbol{n}=8151)$} \\
\hline Primary diagnosis ${ }^{\mathbf{a}}$ & $\mathrm{n}(\%)$ & Primary diagnosis ${ }^{\mathbf{a}}$ & $\mathrm{n}(\%)$ \\
\hline COPD and bronchiectasis & $12,954(25.4)$ & Septicemia & $1176(14.4)$ \\
\hline Pneumonia & $3947(7.7)$ & Acute renal failure & $963(11.8)$ \\
\hline Respiratory failure & $3571(7.0)$ & COPD and bronchiectasis & $944(11.6)$ \\
\hline Asthma & $3255(6.4)$ & Congestive heart failure & $713(8.8)$ \\
\hline Congestive heart failure & $3.019(5.9)$ & Respiratory failure & $623(7.6)$ \\
\hline Septicemia & $1806(3.5)$ & Pneumonia & $579(7.1)$ \\
\hline Cardiac dysrhythmia & $1395(2.7)$ & Asthma & $204(2.5)$ \\
\hline Nonspecific chest pain & $921(1.8)$ & Acute myocardial infarction & $166(2.0)$ \\
\hline Aspiration pneumonitis & $683(1.3)$ & Nonspecific chest pain & $166(2.0)$ \\
\hline Fluid and electrolyte disorders & $666(1.3)$ & Intestinal infection & $158(1.9)$ \\
\hline
\end{tabular}

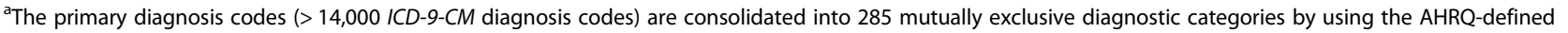
Clinical Classifications Software 
30 and 90 days after their index hospitalization, compared to those without AKI. For clinicians, our findings underscore the importance of prevention of AKI and post-discharge care in this population. For researchers, our findings should facilitate further investigations into the mechanisms underlying the COPD-AKI link to develop preventive and therapeutic interventions in this population with large morbidity burden and healthcare use.

\section{Supplementary information}

Supplementary information accompanies this paper at https://doi.org/10 1186/s12882-020-01780-2.

Additional file 1 : Figure S1. Patient flow of the study. AECOPD, acute exacerbation of chronic obstructive pulmonary disease.

Additional file $\mathbf{2}$ : Table S1. Characteristics of patients hospitalized for acute exacerbation of chronic obstructive pulmonary disease by readmission status. Table S2. Characteristics of patients hospitalized for acute exacerbation of chronic obstructive pulmonary disease by acute kidney injury (complete case analysis). Table S3. Hazard ratio for all-cause readmission during 30-day periods after index hospitalization for acute exacerbation of chronic obstructive pulmonary disease, according to acute kidney injury, overall and stratified by age category and sex (complete case analysis). Table S4. Hazard ratio for all-cause readmission during 90-day periods after index hospitalization for acute exacerbation of chronic obstructive pulmonary disease, according to acute kidney injury, overall and stratified by age category and sex (complete case analysis). Table S5. Hazard ratio for all-cause readmission during 30-day and 90-day periods after index hospitalization for acute exacerbation of chronic obstructive pulmonary disease, according to acute kidney injury and acute kidney injury with dialysis. Table S6. The ten most frequent principal diagnoses of 90-day readmissions in patient hospitalized for acute exacerbation of chronic obstructive pulmonary disease, stratified by acute kidney injury.

\section{Abbreviations}

AECOPD: Acute exacerbation of chronic obstructive pulmonary disease; AHRQ: Agency for Healthcare Research and Quality; AKI: Acute kidney injury; CKD: Chronic kidney disease; COPD: Chronic obstructive pulmonary disease; HCUP: Healthcare Cost and Utilization Project; HRRP: Hospital Readmissions Reduction Program; ICD-9-CM: International Classification of Diseases, Ninth Revision, Clinical Modification; SID: State Inpatient Database

\section{Acknowledgements}

Dr. Hirayama was supported by a grant from the Fulbright Scholarship.

\section{Authors' contributions}

$\mathrm{AH}, \mathrm{TG}$, and $\mathrm{KH}$ conceived the study. $\mathrm{AH}$ and TG analyzed the data. $\mathrm{AH}$ drafted the manuscript. KH supervised the conduct of the study. Finally, all authors contributed substantially to its revision and all authors had access to data. The author(s) read and approved the final manuscript.

\section{Funding}

This study was supported by the grant R01 HS023305 from the Agency for Healthcare Research and Quality (Rockville, MD, USA). Agency for Healthcare Research and Quality did not involve in the design of the study, analysis, interpretation of data and writing the manuscript. The content of this manuscript is solely the responsibility of the authors and does not necessarily represent the official views of the Agency for Healthcare Research and Quality.

\section{Availability of data and materials}

HCUP's Nationwide and State-Specific Databases are available for purchase from the online HCUP distributor (information available at: https://www. hcup-us.ahrq.gov/tech_assist/centdist.jsp).

\section{Ethics approval and consent to participate}

The institutional review board of Massachusetts General Hospital approved this study and the requirement for informed consent was waived.

\section{Consent for publication}

Not applicable.

\section{Competing interests}

The authors declare that they have no competing interests.

\section{Author details}

${ }^{1}$ Department of Emergency Medicine, Massachusetts General Hospital, Boston, MA, 125 Nashua Street, Suite 920, Boston, MA, USA. ²Public Health, Department of Social Medicine, Osaka University Graduate School of Medicine, 2-2, Yamadaoka, Suita, Osaka, Japan. ${ }^{3}$ Department of Clinical Epidemiology and Health Economics, School of Public Health, The University of Tokyo, 7-3-1, Hongo, Bunkyo-ku, Tokyo, Japan.

Received: 15 November 2019 Accepted: 23 March 2020

Published online: 03 April 2020

\section{References}

1. HCUP net. Agency for Healthcare Research and Quality. http://hcupnet.ahrq. gov/. Accessed 24 Dec 2019.

2. Press VG, Konetzka RT, White SR. Insights about the economic impact of chronic obstructive pulmonary disease readmissions post implementation of the hospital readmission reduction program. Curr Oinion Pulm Med. 2018;24(2):138-46. https://doi.org/10.1097/mcp.0000000000000454.

3. Mannino DM, Buist AS. Global burden of COPD: risk factors, prevalence, and future trends. Lancet. 2007;370(9589):765-73. https://doi.org/10.1016/s01406736(07)61380-4.

4. Thadhani R, Pascual M, Bonventre JV. Acute renal failure. N Engl J Med. 1996;334(22):1448-60. https://doi.org/10.1056/nejm199605303342207.

5. Rabb H, Griffin MD, McKay DB, et al. Inflammation in AKl: current understanding, key questions, and knowledge gaps. J Am Soc Nephrol. 2016;27(2):371-9. https://doi.org/10.1681/asn.2015030261.

6. Barakat MF, McDonald HI, Collier TJ, et al. Acute kidney injury in stable COPD and at exacerbation. Int J Chron Obstr Pulmon Dis. 2015;10:2067-77. https://doi.org/10.2147/copd.s88759.

7. Cao CC, Chen DW, Li J, et al. Community-acquired versus hospital-acquired acute kidney injury in patients with acute exacerbation of COPD requiring hospitalization in China. Int J Chron Obstr Pulmon Dis. 2018;13:2183-90.

8. Overview of the State Inpatient Database (SID). Healthcare cost and utilization project. https://www.hcup-us.ahrq.gov/sidoverview.jsp. Accessed 24 Dec 2019.

9. Goto T, Faridi MK, Gibo K, et al. Sex and racial/ethnic differences in the reason for 30-day readmission after COPD hospitalization. Respir Med. 2017; 131:6-10. https://doi.org/10.1016/j.rmed.2017.07.056.

10. Hasegawa K, Tsugawa Y, Tsai C-L, et al. Frequent utilization of the emergency department for acute exacerbation of chronic obstructive pulmonary disease. Respir Res. 2014;15(1):40.

11. Hsu RK, McCulloch CE, Dudley RA, et al. Temporal changes in incidence of dialysis-requiring AKI. J Am Soc Nephrol. 2013;24(1):37-42. https://doi.org/ 10.1681/asn.2012080800.

12. Hsu RK, McCulloch CE, Heung M, et al. Exploring potential reasons for the temporal trend in dialysis-requiring AKI in the United States. Clin J Am Soc Nephrol. 2016;11(1):14-20. https://doi.org/10.2215/cjn.04520415.

13. Goto T, Faridi MK, Gibo K, et al. Trends in 30-day readmission rates after COPD hospitalization, 2006-2012. Respir Med. 2017;130:92-7.

14. Ford ES. Hospital discharges, readmissions, and ED visits for COPD or bronchiectasis among US adults: findings from the nationwide inpatient sample 2001-2012 and Nationwide emergency department sample 20062011. Chest. 2015;147:989-98.

15. Center for Medicare and Medicaid Services. Hospital Readmissions Reduction Program (HRRP). https://www.cms.gov/medicare/medicare-feefor-service-payment/acuteinpatientpps/readmissions-reduction-program/. Accessed 24 Dec 2019

16. Echevarria C, Steer J, Heslop-Marshall K, et al. The PEARL score predicts 90day readmission or death after hospitalisation for acute exacerbation of COPD. Thorax. 2017;72:686-93. 
17. Sawhney S, Marks A, Fluck N, et al. Acute kidney injury as an independent risk factor for unplanned 90-day hospital readmissions. BMC Nephrol. 2017; 18:9.

18. Blecker S, Paul M, Taksler G, et al. Heart failure-associated hospitalizations in the United States. J Am Coll Cardiol. 2013;61(12):1259-67.

19. Hirayama A, Goto T, Shimada YJ, et al. Association of obesity with severity of heart failure exacerbation: a population-based study. J Am Heart Assoc. 2018;7(6).

20. Goto T, Hirayama A, Faridi MK, et al. Obesity and severity of acute exacerbation of chronic obstructive pulmonary disease. Ann Am Thorac Soc 2018;15:184-91.

21. Elixhauser $A$, Steiner $C$, Harris DR, et al. Comorbidity measures for use with administrative data. Med Care. 1998;36(1):8-27.

22. Thompson NR, Fan Y, Dalton JE, et al. A new Elixhauser-based comorbidity summary measure to predict in-hospital mortality. Med Care. 2015;53(4):374.

23. Hsu CN, Lee CT, Su CH, et al. Incidence, outcomes, and risk factors of community-acquired and hospital-acquired acute kidney injury: a retrospective cohort study. Medicine. 2016;95(19):e3674. https://doi.org/10. 1097/md.0000000000003674.

24. Kluth DC, Erwig LP, Rees AJ. Multiple facets of macrophages in renal injury. Kidney Int. 2004;66(2):542-57. https://doi.org/10.1111/j.1523-1755.2004. 00773.x.

25. Doi K, Rabb H. Impact of acute kidney injury on distant organ function: recent findings and potential therapeutic targets. Kidney Int. 2016;89(3):55564. https://doi.org/10.1016/j.kint.2015.11.019.

26. Wu VC, Wang CY, Shiao CC, et al. Increased risk of active tuberculosis following acute kidney injury: a nationwide, population-based study. PLoS One. 2013;8(7):e69556. https://doi.org/10.1371/journal.pone.0069556.

27. Lai TS, Wang CY, Pan SC, et al. Risk of developing severe sepsis after acute kidney injury: a population-based cohort study. Crit Care. 2013;17(5):R231. https://doi.org/10.1186/cc13054.

28. Prowle JR, Echeverri JE, Ligabo EV, et al. Fluid balance and acute kidney injury. Nat Rev Nephrol. 2010;6(2):107-15. https://doi.org/10.1038/nrneph. 2009.213.

29. Siew ED, Parr SK, Abdel-Kader K, et al. Predictors of recurrent AKI. J Am Soc Nephrol. 2016;27:1190-200.

30. Xue JL, Daniels F, Star RA, et al. Incidence and mortality of acute renal failure in Medicare beneficiaries, 1992 to 2001. J Am Soc Nephrol. 2006;17: $1135-42$.

31. Kumar AB, Suneja M. Cardiopulmonary bypass-associated acute kidney injury. Anesthesiology. 2011;114:964-70.

32. Thiele RH, Isbell JM, Rosner MH. AKI associated with cardiac surgery. Clin J Am Soc Nephrol. 2015;10:500-14.

33. Neugarten J, Sandilya S, Singh B, et al. Sex and the risk of AKI following cardio-thoracic surgery: a meta-analysis. Clin J Am Soc Nephrol. 2016;11: 2113-22.

34. Walkey AJ, Wiener RS, Ghobrial JM, et al. Incident stroke and mortality associated with new-onset atrial fibrillation in patients hospitalized with severe sepsis. JAMA. 2011;306(20):2248-54.

35. Davis JD, Olsen MA, Bommarito K, et al. All-Payer Analysis of Heart Failure Hospitalization 30-Day Readmission: Comorbidities Matter. Am J Med. 2017; 130(1):93.e9-93.e28.

36. Storrow $A B$, Jenkins $C A$, Self $W H$, et al. The burden of acute heart failure on US emergency departments. JACC. 2014;2(3):269-77.

37. Waikar SS, Wald R, Chertow GM, et al. Validity of international classification of diseases, ninth revision, clinical modification codes for acute renal failure. J Am Soc Nephrol. 2006;17(6):1688-94. https://doi.org/10.1681/asn. 2006010073

\section{Publisher's Note}

Springer Nature remains neutral with regard to jurisdictional claims in published maps and institutional affiliations.

Ready to submit your research? Choose BMC and benefit from:

- fast, convenient online submission

- thorough peer review by experienced researchers in your field

- rapid publication on acceptance

- support for research data, including large and complex data types

- gold Open Access which fosters wider collaboration and increased citations

- maximum visibility for your research: over $100 \mathrm{M}$ website views per year

At $\mathrm{BMC}$, research is always in progress.

Learn more biomedcentral.com/submissions 